\title{
A PILOT FIELD SURVEY ON THE IN VITRO DRUG SUSCEPTIBILITY OF PLASMODIUM FALCIPARUM IN LAO PDR
}

\author{
TOSHIMITSU HATABU ${ }^{1,2}$, VIENGXAY VANISAVETH ${ }^{3}$, NAO TAGUCHI ${ }^{1}$, \\ JUN KOBAYASHI ${ }^{4,5}$, M. KAIISSAR MANNOOR ${ }^{6}$, HISAMI WATANABE ${ }^{7}$, \\ HIROMU TOMA ${ }^{6}$, SAMLANE PHOMPIDA ${ }^{3}$, and SHIGEYUKI KANO ${ }^{2, *}$ \\ Accepted 20, April, 2005
}

In Southeast Asia, malaria has presented a major public health problem, and the spread of drug-resistant falciparum malaria is making the problem more serious in this region. Thus, evidence-based detection of drug-resistant parasites is important for the accurate evaluation of susceptibility to antimalarial drugs. Lao PDR (Lao People's Democratic Republic) is a developing country in which about $70 \%$ of the population lives in malaria endemic areas. Because of the lack of information on the in vitro drug susceptibility of parasites in this country, chloroquine (CQ) is still the drug of choice for uncomplicated falciparum malaria [1]. This report is a pilot field survey on the in vitro CQ- and mefloquine (MQ)-susceptibility of falciparum malaria using AnaeroPack $^{\circledR}$ gas system in Saravan province, Lao PDR.

Saravan province is located in the southern part of Lao PDR. The survey in this province was conducted from August 8 to 16,2003 . Blood samples were successfully obtained from nine Laotian patients suffering from falciparum malaria. The samples were collected by the staff of the Center of Malariology, Parasitology and Entomology, after explaining the purpose of the study to the patients. The survey was conducted in accordance with the ethical guidelines for epidemiological studies established by the Ministry of Education, Culture, Sports, Science and Technology and Ministry of Health, Labour and Welfare of Japan. The in vitro drug susceptibility test was administered using the AnaeroPack $^{\circledR}$ malaria culture system with a thermostat port- able incubator as described previously [2, 3]. The AnaeroPack ${ }^{\circledR} \mathrm{CO}_{2}$ (Mitsubishi Gas Co., Tokyo, Japan) is a foilpacked paper sachet that on exposure to air immediately absorbs atmospheric $\mathrm{O}_{2}$ and simultaneously generates $\mathrm{CO}_{2}$ until a condition of $15 \% \mathrm{O}_{2}$ and $5 \% \mathrm{CO}_{2}$ is attained. The microaerophilic atmosphere produced within a sealed jar (AnaeroPack ${ }^{\circledR}$ Kakugata jar, SUGIYAMA-GEN Co., Ltd., Tokyo, Japan) can be maintained for at least 24 hours. The temperature inside the portable thermostat incubator (SUGIYAMA-GEN Co., Ltd.) was adjusted to $37^{\circ} \mathrm{C}$. During $P$. falciparum cultivation, the sachet inside the jar was replaced every day when the culture medium was changed. The WHO semi-micro test method was used for evaluation of in vitro drug susceptibility [4]. Briefly, blood samples $(0.1 \mathrm{ml})$ were resuspended in RPMI 1640 (GIBCO BRL), pH 7.4, supplemented with $25 \mathrm{mM}$ HEPES, and sodium bicarbonate. To monitor parasite growth, six wells per plate served as controls without antimalarials. When the schizonts were fully grown in the control wells, the culture plate was removed from the incubator. Thin-smear specimens stained with Giemsa solution were made from each well. We defined parasites as schizonts when they had both dark brown pigment and more than three nuclei [5]. The effect of antimalarials on parasite growth was evaluated by the WHO standard evaluation method.

The results of this study are shown in Table 1 . When complete schizont inhibition is observed at a CQ amount of

1 Gunma University School of Health Sciences, Gunma, Japan;

2 Research Institute, International Medical Center of Japan, Tokyo, Japan;

3 Center of Malariology, Parasitology and Entomology, Vientiane, Lao PDR;

4 Asian Centre of International Parasite Control, Bangkok, Thailand;

5 Bureau of International Cooperation, International Medical Center of Japan, Tokyo, Japan;

6 Division of Tropical Parasitology, Faculty of Medicine, University of the Ryukyus, Okinawa, Japan;

7 Division of Cellular and Molecular Immunology, Center of Molecular Biosciences, University of the Ryukyus, Okinawa, Japan.

* Correspondence:

Shigeyuki Kano,

Research Institute, International Medical Center of Japan

1-21-1 Toyama, Shinjuku, Tokyo 162-8655, Japan

TEL: +81-3-3202-7181 (ext 2877), FAX: +81-3-3202-7287, E-mail: kano@ ri.imcj.go.jp 
Table 1: The results for in vitro drug susceptibility

\begin{tabular}{ccll}
\hline No. & Parasitemia $(\%)$ & Chloroquine & Mefloquine \\
\hline A & 0.015 & Susceptible & Susceptible \\
B & 0.36 & Susceptible & Susceptible \\
C & 1.97 & Susceptible & Susceptible \\
D & 0.91 & Resistant & Susceptible \\
E & 0.01 & Resistant & Susceptible \\
F & 0.13 & Resistant & Susceptible \\
G & 0.002 & Resistant & Susceptible \\
H & 0.004 & Susceptible & Susceptible \\
I & 0.007 & Susceptible & Susceptible
\end{tabular}

$80 \mathrm{nM}$ or less, the parasite is considered susceptible. If schizont formulation is observed at an MQ amount of $640 \mathrm{nM}$ or more, the parasite can be considered resistant. In the present study, four $(44 \%)$ of the nine isolates were resistant to $\mathrm{CQ}$, while all the isolates were susceptible to MQ. There was no correlation between the parasitemia and CQresistance.

The results of this study suggest that CQ-resistant parasites have increased even though CQ is commonly used as the first-line drug for treatment of uncomplicated falciparum malaria in Lao PDR. In neighboring countries such as Thailand and Cambodia, high-grade multi-drug resistant parasites are reported to be spreading and, indeed, in vivo CQ-resistant falciparum malaria has already been reported in Lao PDR [6]. Dedicated efforts have to be made to determine the in vitro drug susceptibility of $P$. falciparum in Lao
PDR as a way to prevent the spread of multi-drug resistant parasites in the near future. This is the first test report on in vitro drug resistance in Lao PDR.

\section{REFERENCES}

1. Guthmann JP, Kasparian S, Phetsouvanh R, et al. The efficacy of chloroquine for the treatment of acute, uncomplicated, Plasmodium falciparum malaria in Laos. Ann Trop Med Parasitol 2002; 96: 553-557.

2 . Hatabu T, Kawazu S, Kojima S, et al. A pilot field trail of an in vitro drug susceptibility test using the AnaeroPack $^{\circledR}$ malaria culture system on the ThaiMyanmar border. Trop Med Hlth 2004; 32: 335-337.

3 . Mizuno Y, Hatabu T, Kawazu S, et al. Cultivation of Plasmodium falciparum isolates under the AnaeroPack $^{\circledR}$ gas condition in a portable thermostatic incubator Jpn J Trop Med Hyg 2000; 23: 393-399.

4 . Rieckmann KH, et al. Drug sensitivity of Plasmodium falciparum- An in vitro microtechnique. Lancet 1978; 7: 9-13.

5 . Silamut $\mathrm{K}$, Phu NH, Whitty $\mathrm{C}$, et al. A quantitative analysis of the microvascular sequestration of malaria parasites in the human brain. Am J Pathol 1999; 155: 395-410.

6 . Pillai DR, Labbe AC, Vanisaveth V, et al. Plasmodium falciparum malaria in Laos: Chloroquine treatment outcome and predictive value of molecular markers. J Infect Dis 2001; 183: 789-795. 